\section{What is already known on this topic}

Speculum examinations to collect cervical smears are the most commonly performed procedures on women

Women dislike undergoing speculum examinations because of fear of pain, embarrassment, or anxiety about feeling vulnerable during the examination

\section{What this study adds}

Women feel less vulnerable and experience less discomfort when examination is carried out without stirrups

the recent attempts to validate self collection methods for cervical cancer screening to eliminate the need for smears. ${ }^{15}{ }^{16}$ Some studies have shown that beliefs about pain during the procedure can influence screening behaviours for some women. ${ }^{13}$

Respect for patients' preferences and ensuring physical comfort are core dimensions of patient centred care, one of the six domains of quality advocated by the Institute of Medicine. ${ }^{17}$ Our findings suggest that examination without stirrups represents a more patient centred way to perform speculum examinations.

Contributors: See bmj.com.

Funding: Uniformed Services Academy of Family Physicians. Competing interests: None declared.

Ethical approval: This study underwent review for ethical considerations by the Institutional Review Board of Eisenhower Army Medical Center.
1 Kahn JA, Goodman E, Huang B, Slap GB, Emans SJ. Predictors of Papanicolaou smear return in a hospital-based adolescent and young Papanicolaou smear return in a hospita- Obstet Gymecol 2003;101:490-9.

2 Larsen M, Oldeide CC, Malterud K. Not so bad after all ... women's experiences of pelvic examinations. Fam Pract 1997;14:148-52.

3 Hoyo C, Yarnall KSH, Skinner CS, Moorman PG, Sellers D, Reid L. Pain predicts non-adherence to Pap smear screening among middle-aged African American women. Prev Med 2005;41:439-45.

4 National Cancer Institute. The Pap test: questions and answers. www.cancer.gov/cancertopics/factsheet/Detection/Pap-test (accessed 20 Oct 2005).

5 Greiver M. No stirrups? Can Fam Physician 2001:47:1979.

6 Klassen D. Preference for the no-stirrup method. Can Fam Physician 2002;48:457.

7 Doig A. De facto evidence for the no-stirrup method. Can Fam Physician 2002;48:876.

8 Curtis P. Personal perspectives on collecting Papanicolaou smears or how I learned to use the stirrups.J Fam Pract 1991;33:345-7.

9 Moettus A, Sklar D, Tandberg D. The effect of physician gender on women's percieved pain and embarrassment during pelvic examination. $A m J$ Emerg Med 1999;17:635-7.

10 Seymore C, DuRant RH, Jay S, Freeman D, Gomez L, Sharp C, et al. Influence of position during examination, and sex of examiner on patient anxiety during pelvic examination.J Pediatr 1986;108:312-7.

11 Thomas A, Weisberg E, Lieberman D, Fraser IS. A randomised contolled trial comparing a dilating vaginal speculum with a conventional bivalve speculum. Aust NZJ Obstet Gynaecol 2001;41:379-86.

12 Olson BK. Patient comfort during pelvic examination. New foot supports vs metal stirrups. JOGN Nurs 1981;10:104-7.

13 Wright D, Fenwick J, Stephenson P, Monterosso L. Speculum 'self-insertion': a pilot study. Women's Health 2005;14:1098.

14 Williams JG, Park LI, Kline J. Reducing distress associated with pelvic examinations: a stimulus control intervention. Women and Health 1992; 18:41-53.

15 Dzuba IG, Diaz EY, Allen B, Leonard YF, Lazcano Ponce EC, Shah KV, et al. The acceptability of self-collected samples for HPV testing vs. the Pap test as alternatives in cervical cancer screening. J Womens Health Gend Based Med 2002;11:265-75.

16 Sellors JW, Lorincz A, Mahony JB, Mielzynska I, Lytwyn A, Roth P, et al. Comparison of self-collected vaginal, vulvar and urine samples with physician-collected cervical samples for human papillomavirus testing to physcian-collocted cervical samples for hunan papilomavisus testing to detect high-grade squamous intraepithelial lesions. CMAJ 2000;163:

17 Institute of Medicine Committee on Quality of Health Care in America. Crossing the quality chasm. Washington, DC: National Academy Press, 2001.

(Accepted 22 May 2006)

doi $10.1136 /$ bmj. 38888.588519 .55

\title{
Commentary: Best practice in primary care
}

Pippa Oakeshott, Phillip Hay

A well done (though necessarily unblinded) trial from the United States shows that women attending for cervical smears feel less vulnerable and have less physical discomfort if a method that doesn't require stirrups is used. $^{1}$ The quality of the smears did not differ, and around half the women were from ethnic minority groups. This trial should change practice in the United States, where many women may be unaware that there is an alternative to using stirrups in cervical screening.

By contrast, in the United Kingdom most speculum examinations for routine cervical smears are done in general practice or family planning clinics and stirrups are not used. Use of stirrups is mainly confined to hospital colposcopy and genitourinary clinics, and leg supporter boards are increasingly preferred.

"For women, the vaginal speculum has loomed large, and has long signified a kind of scrutiny and intrusion [that] they have feared." An unpleasant experience of vaginal examination for a first smear may make women extremely reluctant to attend for cervical screening in future. Examination should always be done by a doctor or nurse who is skilled, sympathetic and gentle. ${ }^{3}$ All health professionals should practice the basic principles of respect, privacy, explanation, and consent for intimate examination (box). These principles are increasingly incorporated in medical and nursing education. ${ }^{4}$

In the UK, cervical screening rates have been shown to be better in practices that have a female partner. ${ }^{5}$ Improved coverage in deprived areas has also been associated with an increase in the number of

\section{Suggested guidelines for conducting vaginal} examinations in primary care ${ }^{3}$

- Explain the reason for doing a vaginal examination and obtain verbal consent

- Offer to find a chaperone and record this in the notes

- Provide privacy to undress and use drapes to maintain the patient's dignity

- Use a closed room and avoid interruptions during the examination

- During the examination: be gentle, explain what you are doing, be alert to indications of distress, avoid personal comments
St George's

Hospital, University of London, London SW17 ORE Pippa Oakeshott reader in general practice

Phillip Hay

reader in genitourinary medicine

Correspondence to: P Oakeshott oakeshot@sgul.ac.uk 
practice nurses, who are often the main providers of cervical screening in general practice. Uptake tends to be lower in practices with more patients who are socially deprived or from ethnic minority groups, ${ }^{5}$ and non-responders may be at increased risk of cervical cancer.

There are alternatives for women who find a conventional speculum examination unacceptable. An Australian study of women attending family planning clinics found that $67 \%(133 / 198)$ agreed to insert their own speculum, and of these, $90 \%$ would choose to do it again. The main barrier was women feeling unsure how to self insert a speculum. ${ }^{6}$ In future, screening might be based on detection of specific human papillomavirus (HPV) subtypes and additional biomarkers for risk of cervical cancer. This might allow the use of self-taken vaginal samples, which could be done either in the clinic or at home. Although response rates might be low, non-responders to cervical screening could be sent postal swabs, and women who are found to have persistent infection with HPV 16 or 18 could be invited to attend for further evaluation.
The paper by Seehusen and colleagues should change clinical practice away from the routine use of stirrups. If cervical screening becomes more user friendly, this could lead to increased coverage. The study also highlights the need for doctors and nurses to respect the patient's integrity when doing vaginal examinations, and shows how trials can be used to assess issues that are important to patients.

We thank Phyllis Moore and Sima Hay for advice.

Funding: BUPA Foundation.

Competing interests: None declared.

1 Seehusen DA, Johnson DR, Earwood JS, Sethuraman SN, Cornali J, Gillespie K, et al. Improving women's experience during speculum examinations at routine gynaecological visits: randomised clinical trial. BMJ 2006;333:171-3

Sandelowski MR. This most dangerous instrument: propriety, power and the vaginal speculum. J Obstet Gynecol Neonat Nurs 2000;29:73-89.

Royal College of Obstetricians and Gynaecologists. Gynaecological examinations: guidelines for specialist practice. London: RCOG, 2002.

Coldicott Y Pope Coldicott Y, Pope C, Roberts C. The ethics of in

teaching to, Cook DG, Ande BMJ, Majeed FA, Cook DG, Anderson HR, Hilton S, Bunn S, Stones C. Using patient and general practice characteristics to explain variations in cervical smear uptake rates. BMJ 1994;308:1272-6.

6 Wright D, Fenwick J, Stephenson P, Monterosso L. Speculum self-insertion: a pilot study. J Clinical Nursing 2005;14:1098-111.

\section{Whooping cough in school age children with persistent cough: prospective cohort study in primary care}

Anthony Harnden, Cameron Grant, Timothy Harrison, Rafael Perera, Angela B Brueggemann, Richard Mayon-White, David Mant

Editorial by Butler, et al

Department of Primary Health Care, University of Oxford, Oxford OX3 7LF

Anthony Harnden university lecturer

Rafael Perera

senior research fellow

in statistics

Angela B

Brueggemann

senior research fellow

in molecular biology

Richard

Mayon-White

epidemiologist

David Mant

professor of general

practice

Department of

Paediatrics,

University of

Auckland, Starship

Children's Hospital,

Auckland, New

Zealand

Cameron Grant

associate professor of

paediatrics

continued over

BMJ 2006;333:174-7

\section{Abstract}

Objective To estimate the proportion of school age children with a persistent cough who have evidence of a recent Bordetella pertussis infection.

Design Prospective cohort study (October 2001 to March 2005).

Setting General practices in Oxfordshire, England. Participants 172 children aged 5-16 years who presented to their general practitioner with a cough lasting 14 days or more who consented to have a blood test.

Main outcome measures Serological evidence of a recent Bordetella pertussis infection; symptoms at presentation; duration and severity of cough; sleep disturbance (parents and child).

Results 64 (37.2\%, 95\% confidence interval 30.0\% to $44.4 \%$ ) children had serological evidence of a recent Bordetella pertussis infection; 55 (85.9\%) of these children had been fully immunised. At presentation, children with whooping cough were more likely than others to have whooping (odds ratio 2.85, 95\% confidence interval 1.39 to 5.82$)$, vomiting $(4.35,2.04$ to 9.25$)$, and sputum production (2.39, 1.14 to 5.02$)$. Children with whooping cough were also more likely to still be coughing two months after the start of their illness $(85 \% v 48 \% ; \mathrm{P}=0.001)$, continue to have more than five coughing episodes a day $(\mathrm{P}=0.049)$, and cause sleep disturbance for their parents $(\mathrm{P}=0.003)$.
Conclusions For school age children presenting to primary care with a cough lasting two weeks or more, a diagnosis of whooping cough should be considered even if the child has been immunised. Making a secure diagnosis of whooping cough may prevent inappropriate investigations and treatment.

\section{Introduction}

School age children with a persistent cough present general practitioners with diagnostic and management dilemmas. A precise diagnosis is often difficult for the doctor, but parents are anxious for an explanation. Children commonly receive empirical treatment for asthma and may be referred for further investigation. ${ }^{1}$ These investigations often fail to yield a clinical reason for the cough, which can last for months.

Studies in the United States report a 20\% incidence of Bordetella pertussis infection among adults with a persistent cough. ${ }^{2}$ Despite data showing that neither infection nor immunisation results in lifelong immunity, whooping cough is seldom diagnosed in primary care because of the lack of specificity of clinical symptoms and signs. Whooping cough is perceived as a disease of very young children who have not been immunised and who have classic features such as whoop. Notifications among older children in England and Wales have been low for several years. ${ }^{3}$

This article was posted on bmj.com on 7 July 2006: http://bmj.com/cgi doi/10.1136/bmj.38870.655405.AE 